\title{
PREFACE TO THE PAPERBACK EDITION
}

$\mathrm{T}$ hese pages provoked the controversy I had expected. Responses have ranged from total condemnation to excitement and relief that a critic from the left has at last shed light on what has become known as the 'Chomsky problem'. Like any writer, I was buoyed by the enthusiastic support, and stung by the critical voices. Encouragement from so many scientists and activists whom I have always admired kept me going when Noam Chomsky publicly denounced my book as 'complete nonsense throughout', and called my whole account 'a wreck.'

So what exactly is the 'Chomsky problem'? In essence, it's the difficulty of seeing the connection between Chomsky the scientist and Chomsky the political activist. Put more starkly, it's the difficulty of grasping just how Chomsky succeeded in reconciling his passionate hostility to the military with his lifelong employment in a military lab. I argue that it was Chomsky's commitment to political principle that impelled him to drive such a massive wedge between these two sides of his life.

As I delve into half-forgotten details, you may well ask, 'Why should we care?' My answer is this: Chomsky was and remains the towering figure in a philosophical movement - known today as the 'cognitive revolution' - the effects of which have come to dominate much of Western thought. As this post-war intellectual upheaval rippled through US academia and reverberated across the globe, the fissure between Chomsky's science and his activism widened steadily into a chasm which we all feel today. Under relentless sociological pressure, the notion of a wholly neutral, politically disinterested science is now popularly perceived as the preserve of an establishment elite set apart from the rest of us as we struggle to make sense of our lives. Meanwhile, the majority of activists have become more and more 
estranged from this entire way of perceiving and engaging in science. The outcome has been an institutionally enforced disconnect between science and activism whose damaging consequences, particularly in an era of potentially catastrophic climate change, have become all too clear.

Our current state of knowledge resembles a broken mirror, each fragment telling its own story. We need to put together the big picture, fighting for conceptual unification regardless of the political consequences. You can't get away from politics - from power differences and conflicts of interest. In principle, however, scientific research involves accountability and collaboration on a level transcending such things. The scientific community needs to defend itself against political interference, no matter how cleverly it is concealed. If science is to come first, we don't have a choice as to whether to become politically active. If you're inactive, you're colluding in someone else's politics.

To understand the crucial role played by Chomsky in all this, let me take you back to his very first job interview in 1955. It was for a post in a military lab in Boston, the Cold War by this stage well under way. The successful applicant would join a team at the Massachusetts Institute of Technology working on machine translation, a project heavily funded by the Pentagon with military applications in mind. ${ }^{2}$ Noam Chomsky attended the interview but had other ideas. Detesting the whole concept of military research, he explained that he wasn't interested in machine translation and wouldn't help. On that understanding, he was given the job. From then on, according to Chomsky, he never touched machine translation at all.

His own portrayal of that paradoxical situation perfectly encapsulates my theme. Chomsky is in his surroundings yet outside them, bodily present yet mentally elsewhere, working for the military while determined to produce nothing they could use. The detached otherworldliness of his linguistics, if my argument is correct, served Chomsky well as he struggled with the moral dilemmas he faced. Only by redefining language as something utterly abstract and ideal - completely removed from social usage or any possible practical application - could he eliminate the danger that his work might assist the military in killing people. He would cooperate loyally with his laboratory colleagues, but confine himself to pure science.

Since Chomsky and his supporters deny my whole story, I can only respond by recalling details of documentary sources and memories on which all sides roughly agree.

It was the celebrated Russian linguist Roman Jakobson who had suggested to Chomsky that he secure that crucial interview. The interviewer that day was Jerome Wiesner, then the director of the Research Laboratory of Electronics (RLE) and one of the most influential military scientists in 
the country. Explaining his interest in the young linguist, Wiesner recalls: 'Professor Bill Locke suggested we use computers to do automatic translation, so we hired Noam Chomsky and Yehoshua Bar-Hillel to work on it.' ${ }^{3}$ Wiesner had good reason to view Chomsky as an ideal catch. After all, the candidate already had experience with automatic rewrite rules and related procedures for arriving at logical operations accessible in principle to a machine. Illustrating his dry sense of humour, Chomsky recalls what he said to Wiesner in that interview:

I told him, I don't think the project makes any sense. The only way to solve this problem is brute force. What's going to be understood about language is not really going to help and I'm just not interested, so I'm not going to do it. He thought that was a pretty good answer. So he hired me on the machine translation project. But mainly to do what I felt like. ${ }^{4}$

We may regret that Chomsky never got to write a beginner's manual for handling job interviews. 'Always turn the tables' might well have been his advice. From then on, nothing in his attitude to authority would change.

To savour the paradoxes of Chomsky's subsequent employment, it helps to know more about Wiesner. In terms of US military policy, Chomsky remembers him as a dove: 'He was on the extreme dovish side of the ... Kennedy administration. But he never really accepted the fact that the students and the activists considered him a kind of a collaborator. ${ }^{5}$ This double-edged evaluation suggests to me that Chomsky knew from the outset about Wiesner's deep involvement with the Pentagon, but out of respect for his boss, left it to others to condemn him on those grounds.

A specialist in communication engineering, between 1952 and 1980 Wiesner rose from director of the RLE to provost and then president of MIT, in effect making him Chomsky's boss for over twenty years. ${ }^{6}$ It is easy to see why, in Chomsky words, the students and the activists considered him a kind of collaborator'. After all, it was Wiesner who, in the 1950s, had brought nuclear missile research to MIT. ${ }^{7}$ He was particularly proud of the fact that his Research Laboratory of Electronics - centrally situated on MIT's campus - had made 'major scientific and technical contributions to the continuing and growing military technology of the United States. ${ }^{8}$

In 1971, the US Army's Office of the Chief of Research and Development published a list of what it called 'just a few examples' of the 'many RLE research contributions that have had military applications'. The list included 'beam-shaping antennas', 'helical antennas', 'microwave filters', 'ionospheric communication', 'missile guidance, 'atomic clocks', 'signal 
detection', 'communication theory,' 'information and coding theory', 'human sensor augmentation' and 'neuroelectric signals. ${ }^{9}$ Given the military significance of all such projects, Chomsky would have his work cut out disentangling his own theories about language from any possible military use. ${ }^{10}$

But Wiesner's contribution to the US military was far greater than his involvement with MIT. One major achievement, he reminds us, was that he 'helped get the United States ballistic missile program established in the face of strong opposition from the civilian and military leaders of the Air Force and Department of Defense. He adds that he 'was also a proponent of the Polaris missile system, the ballistic missile early warning system, and the satellite reconnaissance systems. ${ }^{11}$ By 1961, Wiesner had become President Kennedy's chief science adviser and it was from this influential position that he was able to insist that nuclear missile development and procurement 'must all be accelerated.' ${ }^{12}$ To justify this military build-up, Kennedy invoked the myth of America's weakness compared with the Soviet Union - the total fiction of a 'missile gap' that, according to Wiesner's own account, 'I helped invent.' ${ }^{13}$

After Kennedy's assassination, Wiesner's power declined. However, he was still able to contribute to the US war effort by bringing together a team of leading scientists in a project to design and deploy a vast barrier of sensors, mines and cluster bombs along the border between North and South Vietnam. ${ }^{14}$ Wiesner's long-standing involvement with nuclear decision-making, and his consequent awareness of just how flawed and dishonest the whole process was, did lead him to criticize the unrestrained stockpiling of nuclear missiles, particularly those equipped with multiple warheads. But this change of heart did not stop him from continuing to run MIT laboratories dedicated to research on just such developments. ${ }^{15}$

Wiesner stepped down as MIT's president in 1980, but what the university's representatives call its 'deep relationship' with the Pentagon continues to this day. ${ }^{16}$ Since 1980, MIT's on-campus research has included work on missiles, space defence, warships, nuclear submarines, IEDs, robots, drones and 'battle suits. ${ }^{17}$ At one point in the 1980s, work on biological weapons was brought to the university by its provost, John Deutch, who, it is said, went as far as to pressure junior faculty into performing this research 'on campus. ${ }^{18}$

MIT's military involvement is not in doubt. But then we come on to a quite different question. No matter what I say, neither Chomsky nor his supporters seem able to acknowledge that my argument throughout this book is not that Chomsky colluded with the military, but that he had to move mountains to avoid doing so - and resoundingly succeeded in that aim.

Responding as if I were condemning him, Chomsky, at times, comes close to denying that MIT had any involvement with war research at 
all. Early in 2017, I teamed up with Chomskyan linguists Neil Smith and Nicholas Allott to convene a conference in London to celebrate the fiftieth anniversary of Chomsky's legendary anti-war intervention, 'The Responsibility of Intellectuals. Chomsky agreed to participate by live video link and, on the day, was asked to comment on a range of issues. One question concerned any conflicts he may have felt while employed within a Pentagon-funded institution famed for its military research. Chomsky replied that the question was based on a misunderstanding, since, with the exception of certain departments, 'MIT itself doesn't have war work. ${ }^{19}$

'There was zero military work on campus', Chomsky again stated in direct response to my book, having adopted this line of argument as his standard reply. ${ }^{20}$ As Decoding Chomsky was arriving in bookshops, a New York Times journalist asked him directly: 'How about Chris Knight? He connects your theory of language to Pentagon-funded work you did at MIT during the Cold War.' Chomsky agreed about the military funding but went on: 'Does this mean we were doing military work? There was a study in 1969, the Pounds Commission - I was a member of it - to investigate whether any military or classified work was being done on campus. Answer? None.21

This frequently repeated claim is so strange - so starkly at odds with the truth - that it demands an explanation. To my mind, it simply confirms that when Chomsky says such things, it is his moral conscience that we hear speaking to us loud and clear.

Let me stress that I do believe Chomsky's moral claim, since I accept that none of his own research could possibly have aided the US military in any way. But this cannot apply to his institution as a whole. Chomsky apparently feels that in order to deny his personal involvement in war research, he has no choice but to deny MIT's involvement. He can make that wider claim only by invoking one particular study published in 1969 .

As I show in Chapter 4, the Pounds Commission - named after its chair, William Pounds - was set up by Chomsky's employers in response to a virtual uprising by students against MIT's war research. In an attempt to pacify the students, MIT insisted that, although it did administer some labs working directly on weapons, these labs were not really part of the university because they were 'off campus'. As a member of the Pounds Commission, however, Chomsky signed an appendix to its final report which shows that as many as 500 students and academics worked at these 'off-campus' military labs. ${ }^{22}$ In subsequent interviews, Chomsky is on record as stating that 'the labs were very closely integrated' with MIT, some being located only 'two inches off campus.'23

In another interview he was clearer still: 
There was extensive [military] research on the MIT campus. There were laboratories at MIT that were involved, for example, in the development of the technology that's used for ballistic missiles, and so on. In fact, a good deal of the missile guidance technology was developed right on the MIT campus and in laboratories run by the university.

Now, for reasons of transparency, Chomsky wanted all such military work kept on campus:

First, should this work be done at all? ... Assuming that the work shouldn't be done, then the concrete and crucial question arises: Shall we get it off campus? ... Now, my feeling is that if the work is going to be done, I'd rather have it done on campus. That is, I'd rather have it be visible, have it be the center of protest and activism, rather than moving it somewhere else where it can be done silently, freely, the same people doing it, often, in fact, by just changing the name of the connection ...

At this point, as I show in Chapter 4, Chomsky goes out of his way to reject the whole idea of management smokescreens designed to hide what was going on:

In fact, my proposal, and I meant this quite seriously, was that universities ought to establish Departments of Death that should be right in the center of the campus, in which all the work in the university which is committed to destruction and murder and oppression should be centralized. They should have an honest name for it. It shouldn't be called Political Science or Electronics or something like that. It should be called Death Technology or Theory of Oppression or something of that sort, in the interests of truth-in-packaging. ${ }^{24}$

In the event, Chomsky's novel proposal was not accepted by either the Pounds Commission or MIT's managers. Instead, the university decided to divest itself of the labs working directly on nuclear missiles, while continuing to administer the huge Lincoln Laboratory which really was located off campus - in an Air Force base well away from student protesters. But my point here is that by taking a stand on the geographical location of MIT's missile labs, urging their retention on campus, Chomsky was openly acknowledging his university's deep involvement with them. Some years before the Pounds Commission, in 1967, he had been worried enough to consider quitting MIT altogether. In a letter to George Steiner, which I 
quote in this book, Chomsky recounts how he had 'given a good bit of thought to ... resigning from MIT' because of its 'tragic and indefensible' involvement in the Vietnam War. ${ }^{25}$

Let me now turn to Chomsky's second criticism of my argument in these pages. He says that the US military didn't care about the research they were paying for at MIT, adding that even if they did care, his own linguistic research would certainly have been of no interest to them. My error here shows that, in Chomsky's words, I am 'deeply confused about the work on linguistics that I and others are doing. The military, Chomsky claims, were unconcerned with such things: 'There was no interest of the sort, and if there had been, it would have had nothing at all to do with our studies of universal grammar. ${ }^{26}$

Chomsky is technically right when he says that the Pentagon did not involve itself in the day-to-day running of the university. But this is hardly surprising. As we have seen, Chomsky's boss Jerome Wiesner worked directly for the Pentagon and so was well able to represent its interests. Secondly, Wiesner had long known that what he called the anarchy of science' needed to be protected if the Pentagon's research institutes were to foster sufficient creativity for novel insights to emerge. ${ }^{27}$

Since publication, I have come across a 1946 directive by no less a figure than General Eisenhower, insisting that in order to enable military scientists across the US 'to make new and unsuspected contributions', they 'must be given the greatest possible freedom to carry out their research. ${ }^{28}$ Chomsky's recollection that he and his colleagues felt free from military interference does not mean that the military had 'no interest' in what was going on. To take just one example, in 1968 the deputy director of the Office of Naval Research in Boston wrote that his scientists 'have been close' to the RLE's research programmes 'from the beginning' and 'have provided much valuable advice and counsel to the directors and working scientists. ${ }^{29}$

In yet another response to my argument, this time in the London Review of Books, Chomsky counters that his linguistic approach has remained consistent throughout his career, whether he had military funding or not. This, he says, constitutes sufficient proof that funding considerations had no influence on his work. ${ }^{30}$ That is easy to answer. Even during Chomsky's early years at Harvard, when he had no military funding, both he and his wife, Carol, were already working in close association with philosophers and computer scientists at MIT's Research Laboratory of Electronics. ${ }^{31}$ As I show in the book, well before he got his paid job at MIT, Chomsky's concept of language had been developed under the influence of an intellectual culture heavily shaped by military preoccupations. Even as Pentagon 
funding of linguistics declined, this intellectual culture lived on. And, of course, no one expects an academic who has committed his entire career to a particular paradigm to discard it and switch to some other idea just because the funding changes or stops.

Despite all this, Chomsky is insistent and continues to dismiss any suggestion of a connection between his own work and the militarily shaped intellectual culture then prevailing at MIT. In particular, he denies any link with Warren Weaver's ideas. In fact, Weaver was the Rockefeller Foundation director who had pioneered machine translation at MIT. It was he who first floated the idea that if an underlying logical structure common to the world's language could be found, automatic translation might proceed by encoding sentences first into this structure and then out again into whatever locally spoken language was required. I have argued that it was hardly surprising that when Chomsky offered his own apparently similar concepts - automatic 'rewrite rules', 'kernel sentences', 'deep structure', 'universal grammar' and so forth - his laboratory colleagues imagined these to be connected in some way with Weaver's visionary project and hence with their own technical concerns.

In reality, Chomsky had no interest in developing a universal language because he suspected that humans already possess just one underlying language. Neither did he go along with Weaver's enthusiasm for machine translation. But enough people in the 1950s shared Weaver's dream to make Chomsky's research programme seem a perfect way of turning it into reality. MIT's laboratory technicians and computer scientists would surely have been astonished had Chomsky informed them that there was no connection at all.

But Chomsky still holds his ground. When we exchanged emails, he told me that universal grammar was not remotely connected with anything Weaver may have dreamed of. While I accept the distinction, it was generally known that machine translation at MIT was Weaver's baby and that Chomsky had been recruited to work on it. Just about all those involved expected Chomsky's theoretical labours to be relevant in some way. In 1957, one MIT manager summed up the mood by reporting that Chomsky's new book, Syntactic Structures, 'may provide a new theoretical foundation for all work on the machine processing of verbally expressed information. ${ }^{32}$ In a widely read review of the same book, Robert Lees wrote that 'Chomsky's conception of grammar may prove to be of the utmost importance [in] the field of machine translation. ${ }^{33}$ In 1958, Yehoshua Bar-Hillel again voiced the assumption, shared by virtually all MIT insiders, that Chomsky's work on basic linguistic theory should, 'in due time, be turned into a new method of 
machine translation. ${ }^{34}$ So even if Chomsky didn't see a connection with Weaver's machine translation project, it's clear that others did.

When Weaver first glimpsed the possibilities of machine translation, a key part of his inspiration was Alan Turing's recent breakthrough in the mathematics of computing. Revealing his roots in the same intellectual culture, Chomsky stresses how his early formulations depended critically on 'the modern theory of computability, which was developed by Alan Turing and other great mathematicians of the 1930s and 1940s. ${ }^{35}$ To trace this common ancestry - to point out some relationship - is not to conflate Chomsky's approach with Turing's or Weaver's. Needless to say, Chomsky's concepts and theories were uniquely his own. Yet, to his admirers in the RLE in the early years, it seemed self-evident that Chomsky's symbolic strings and mechanical rewrite rules were designed to assist them in developing computer software for processing language.

My own explanation for all this confusion is that when Chomsky was specifically asked about the relevance of his work to software development or automatic processing, his impulse was to insist that he only ever worked on basic theory. I have no doubt that in Chomsky's case, his work genuinely did have no military applications. Despite this, I am reminded of Professor Jonathan King's description of how MIT graduate students described their weapons research during the 1980s:

There were hundreds and hundreds of physics and engineering graduate students working on these weapons, who never said a word, not a word ... So you'd go and have a seminar on the issue they're just working on; you know, they're working on the hydrodynamics of an elongated object passing through a deloop fluid at high speed. 'Well, isn't that a missile?' 'No, I'm just working on the basic principle; nobody works on weapons.'36

So that's how it worked. Whatever you were doing for the military, there was always a 'basic principles' way of obscuring what was going on.

Not only does Chomsky deny that the military had any interest in his research, he goes an important step further when he claims that the myth of Pentagon funding was just an administrative device enabling state funding of basic research. An interview exchange between Chomsky and historian Howard Gardner runs as follows:

Gardner: 'But is it true that initially your work was funded because the military did want to take what you were doing and use it for translation and ...? 
Chomsky: 'That's actually a widespread illusion ... It's very widely believed but basically the military didn't care what you were doing ... The military didn't care. What the military was doing was serving as a kind of a funnel by which taxpayer money was being used to create the high-tech economy of the future ... This was just US industrial policy. The way you develop the economy of the future was by the government, meaning the taxpayer, funding research and ultimately handing it over to private corporations for profit... The Pentagon happens to be a natural way of funding electronics based research and development. ${ }^{37}$

There may well be some truth to this argument. Yet the Pentagon itself has said that it makes 'a very thorough effort' to ensure that it funds 'only research projects directly relevant to the military's technological needs'. And, when exhaustively checked by a group of anti-militarist academics from Stanford University, this claim was found to be essentially accurate. ${ }^{38}$

Whatever we think of these conflicting arguments, we can be confident that when the US military invests resources in university research, it does so for reasons of its own. Contrary to his flat rebuttal of the entirety of my book, Chomsky often lets slip that, deep down, he has few illusions about any of this - as when he commented, 'I'm at MIT, so I'm always talking to the scientists who work on missiles for the Pentagon.' Or again, at the height of the student protests in 1969, when Chomsky criticised an MIT student for saying 'What I'm designing may one day be used to to kill millions of people. I don't care. That's not my responsibility. I'm given an interesting technological problem and I get enjoyment out of solving it', he commented that he could name twenty MIT faculty members 'who've said the same thing. ${ }^{39}$

Like so many authors, I had no sooner committed to print than I discovered a wealth of resources I wish I had known about earlier. Let me single out an unpublished $\mathrm{PhD}$ thesis - 'Private knowledge, public tensions: Theory commitment in post-war American linguistics' - which was submitted by Janet Nielsen to the University of Toronto in 2010. From my standpoint, the value of this groundbreaking study is the way in which it describes, in unprecedented scholarly detail, the subtle mechanisms through which the Pentagon's funding priorities shaped the prevailing intellectual culture at MIT. Nielsen's insights have served to put the final pieces of the jigsaw puzzle into place.

Of particular interest were the chapters dealing with 'private knowledge'. Nielsen describes in vivid detail the extraordinary bubble of mutual reference, exclusivity and circularity inhabited by Chomsky and his colleagues 
during their early years at MIT. Partly, this reflected an earlier tradition of relying on internal reports. In a laboratory where technicians and engineers were experimenting with the design of military gadgets, there was neither the need nor the incentive to publish in international journals. On top of that, the need to classify projects as top secret severely restricted opportunities for publication conditional on peer review. For these and other reasons, the prevailing culture had been to rely heavily on private reports of conversations, mimeographed sheets of paper, unpublished notes and selfreferencing, rather than peer-reviewed journal articles available for all to scrutinize and assess.

In fairness, it needs to be said that even for those working on basic theory, there were very few opportunities for journal publication at the time. Even where a suitable journal existed, Chomsky and his colleagues felt that developments were happening so fast that they could hardly be expected to wait while an out-of-touch editor sat on exciting new results for months on end. But Nielsen's point is that the combined effect of such a culture was to encourage in Chomsky and his followers a sense that they could legitimately escape all normal scholarly constraints. She shows how their reliance on private knowledge made them a closed inner circle, whose feelings of exclusivity and superiority led outsiders to perceive them as an intentionally secretive cult. Nielsen explains:

The underground literature culture was a defining part of transformational grammar for over a decade, arising quickly in the late 1950s and persisting until the close of the 1960s. The existence of such a culture is, seemingly, at odds with the value placed on academic freedom and open scientific knowledge in the mid to late 20th century. In other disciplines from biology to physics, publication in mainstream journals and the open circulation of knowledge was the norm. Among other advantages, it was considered necessary in order to claim intellectual priority. ${ }^{40}$

Admittedly, post-war American physicists frequently exchanged prepublication copies of papers submitted to or accepted by mainstream journals. But, unlike the transformational grammar literature, such preprints were not private knowledge but means of bringing exciting new results immediately to the physics community worldwide. 'In contrast', writes Nielsen, 'transformational grammarians were riding on what they saw as the cutting edge of linguistics, and yet shunned mainstream journals and publication mechanisms.' Since external critics were thereby denied any way of evaluating developments at MIT, they tended to give up in 
disgust or despair. Their bad-tempered withdrawal from workshops and conferences served only to reinforce the conviction among believers that MIT outsiders were incapable of understanding the new results, hence unworthy of being granted access to this work.

Enlightened by Nielsen, I can better understand how it was that Chomsky and his followers were able to elbow aside all opposition, treating every other paradigm as deserving of scorn. They enjoyed substantial military funding, benefited from their location in a prestigious military lab, and felt no need to debate as equals with linguists from other backgrounds. It did not matter that each new incarnation of Chomsky's theory had a relatively short life. It did not matter that nothing, ultimately, made very much sense. Transformational grammar was so much the institutionally favoured paradigm that no rival approach could hope to compete. Add to that Chomsky's brilliance in negotiating the political landscape, condemning the US military from which his own institution derived funding and support, and we have the most influential intellectual of our age.

For anyone in my position as a lifelong activist, it feels risky to say things which can so easily be misunderstood. Certain of Chomsky's claims don't match the historical facts. Yet, viewed in context, they make sense as rational responses to genuine dilemmas. No part of my account can detract from Chomsky's record as a tireless anti-militarist campaigner, whether organizing draft resistance in the 1960s or giving inspirational lectures across the world in more recent decades. Neither can it detract from his persistence in withstanding the institutional pressures that he must have come under at MIT. Had he resigned in disgust in 1967, when he was thinking of doing so, he might never have gained the platform he needed to signal his dissidence across the world. There are times when all of us have to make compromises, some more costly than others. I have argued that in Chomsky's case it was his science rather than his activism which bore the brunt of those damaging pressures and costs. Despite everything, Chomsky the activist remains an inspiration to us all. If politicians were honest and governments told the truth, we would have no need of such a figure. But in an imperfect world, we do need him. If Noam Chomsky did not exist, we would have to invent him. 